\title{
XLV. Notice upon the analyses of the chromate of iron, and upon the variety of the epidote called zoysite
}

\section{Hauy}

To cite this article: M. Hauy (1808) XLV. Notice upon the analyses of the chromate of iron, and upon the variety of the epidote called zoysite , Philosophical Magazine Series 1, 30:119, 223-225, DOI: $10.1080 / 14786440808563807$

To link to this article: http://dx.doi.org/10.1080/14786440808563807

曲 Published online: 18 May 2009.

Submit your article to this journal $\pi$

Џll Article views: 2

Q View related articles $\sqsubset$ 
On the Analyses of the Chromate of Iron, Be. 223

The abracum is prepared from white mica, by repeated grindings, the finer particles being removed tor use by washing them from the grosser parts.

The wall, when finished in this manner, shines like the scales of a fish; and when the room is lighted has a splendid appearance: but in the day-time, the wall washed with the powdered potstone alone, in my opinion, looks better than when washed with either quick-lime or mica.

XLV. Notice upon the Analyses of the Chromate of Iron, and upon the Variety of the Epidote called Zoysite. By M. $\mathrm{HAUY}_{\text {A }}$.

M. Laugrer has published in a former number of these Annales $\uparrow$, the result of the analysis he made of the chromate of iron of Siberia, and this result was similar to that obtained by M. Vauquelin, when examining the chromate of iron discovered by $M$. Pontier in the department of Var. M. Klaproth lately repeated the analysis of the same substance upon a piece which came from Krieglach, in Styria; and his results having been communicated to $M$. Laugier, we now insert it, as presenting a confirmation of the two preceding analyses.

\section{KLAPROTH.}

Chromate of Iron of Styria.
LAUGIER.

Chromate of Siberia chromate of Var.

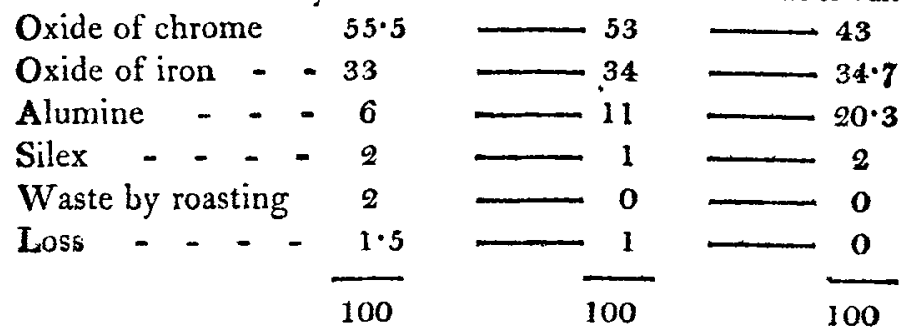

We find in a subsequent number the result of another analysis made by $M$. Laugier upon a grayish substance

* From Annales du Muséum d'Histoire, tome iz. p. 108. t See Phil. Mag, vol, xxiv, p. 3 . 
224 On the Analyses of the Chromate of Iron, \&8.

brought from the Valais, which I recognised from its structure and physical properties to be a variety of the epidote, although it differed in its external characters from the crystals of this species hitherto observed. M. Laugier found that the respective quantities and qualities of its component principles were the same as in the epidote of Arendal, and in that of France, analysed by M. Vauquelin and M. Descostils.

The same variety also exists in Carinthia and in some of the neighbouring countries; and $M$. Werner has since given the name of zoysite to it in honour of baron Zoys. The distinction which $M$. Werner establishes between this substance and our epidote is in some measure a consequence of the nomenclature adopted by this celebrated naturalist; for he gives to the epidote the name of Pistazite (Pistachio stone) because it is generally of a more or less deep green. Now this name seems to exclude the zoysite, the colour of which is gray, brown, or brownish yellow, but never green; at least it is so in those specimens we have seen.

M. Laugier has been informed that Messrs. Klaproth and Bucholz have recently analysed the zoysite ; and the following are their results, compared with those of the French chemist.

KLAPROTH.

Gray Epidote, said to be Zoysite.
LAUGIER.

The same Substance. The same Substance.

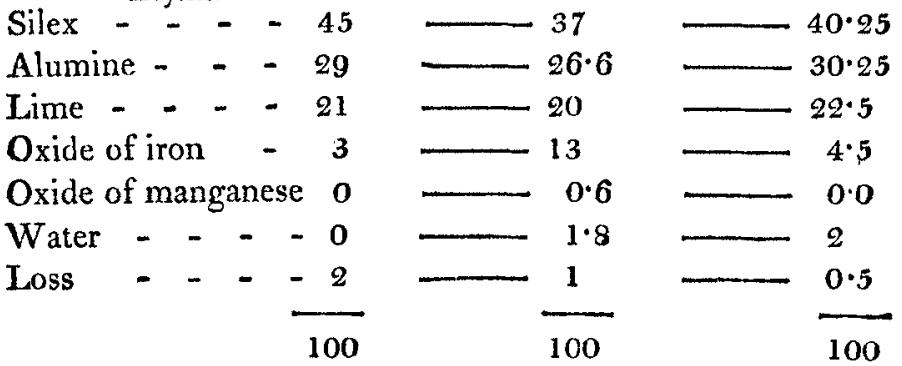

If we compare these three results either with each other or with the others which have for their objects the epidotes of Norway and France; and if on the one hand we consider the agreement which exists between chemistry and the 
yeometry of crystals, we shall find the most convincing proofs that the zoysite should be joined to the epidote, like the mineral of Norway, which a deceitful indication of its characters had made to be placed in a particular species under the names of arendalite and akanticone.

XLVI. On drying Articles of Manufacture, and heating Buildings, by Steam. By R. Buchannan, Esq., Civil Engineer, Glasgow.

To Mr. Tilloch.

$M_{A N Y}$ additional facts with regard to heating by steam have lately been ascertained in this neighbourhood, and its application to various processes in manufactures continues to increase. Mr. Richard Gillespie is highly pleased with its effects upon copper-plate callico-printing at his works, as also for heating his calenders. For this last purpose, and to warm his warehouse and counting-house, the steam is conveyed to a distance of above ninety-three yards.

Steam was, I believe, tried many years ago at Leods, for drying goods, as a substitute for stoves; but for some reason, of which I am ignorant, was abandoned. Mr. Lounds, at Paisley, however, has for a considerable time used it with great success in drying fine muslins. Messrs. Leys, Mason and Co. now also use it at their bleaching works, at Aberdeen.

Some kinds of muslins have for several years been dried by being rolled round cylinders of tin plate filled with steam, but I do not here allude to that mode.

For drying of dyed yarn and pullicates, (a kind of coloured chequed cotton handkerchiefs,) a higher temperature than for fine muslin is required. I am glad, however, to have it in my power to say, that Messrs. Muir, Brown, and Co., at their dveing and bleaching works here, have found steam to answer those purposes much better than the usual mode by stoves. Mr. Muir informs me, that, although they formerly gave out their pullicates to be bleached

Vol. 30. No. 119. April 1808. 